УДК 658.8:629.366(476)

DOI: https://doi.org/10.26642/jen-2019-4(90)-94-99

А.Г. Шумилин, д.э.н., доц. В.В. Можджер, ген. директор

\title{
Новые подходы к сбытовой деятельности ООО «Беларус Трактор» (Будапешт) как предприятия товаропроводящей сети
}

\begin{abstract}
В статье рассматривается сбытовая деятельность ООО «Беларус Трактор» на европейском рынке в контексте общего экспорта. Анализируется рынок тракторов Венгрии, запросы фермеров, позиции конкурентов, наиболее эффективные методы продажи сельхозтехники. Проанализированы динамика продажи тракторов «Беларус» в сравнении с другими производителями и достигнутье результаты. Предложень такие формь коммерческой работы «Беларус Трактор», как ивент-сбыт, интернет-сбыт, рекламная деятельность, участие в соревнованиях по пахоте и др.
\end{abstract}

Ключевые слова: сбытовая деятельность; ивент-сбыт; интернет-сбыт; мТЗ; «Беларус Тактор».

Постановка проблемы. Для Минского тракторного завода (МТЗ) важнейшим показателем успешности его деятельности является сбыт продукции. Содержание сбытовой деятельности определяется совокупностью технологических и организационно-коммерческих функций, регулируется сбытовой политикой.

Сбытовая политика МТЗ направлена на завоевание и расширение своего рынка, поиск новых заказчиков, постоянную работу с уже имеющимися клиентами. В ходе реализации сбытовой политики МТ3 формируются конкретные экономические и финансовые результаты деятельности завода, проявляется уровень конкурентных преимуществ продукции.

Эффективность сбытовой деятельности во многом зависит от работы маркетинговых служб, связанных с мониторингом рынка, его сегментированием и позиционированием. На МТЗ функционирует маркетинг-центр, который организован по функциональному принципу с элементами товарно-рыночного и территориального управления. Для реализации своих функций маркетинг-центр активно взаимодействует практически со всеми подразделениями, и сам является основным подразделением завода. В маркетинг-центре на основе экономического анализа и изучения конъюнктуры рынка формируется не только сбытовая политика, но и стратегия развития МТЗ.

Продвижение товара, взаимодействие завода с дилерами и партнерами, доведение продукции до потребителя и ее реализация осуществляется через товаропроводящую сеть (ТПС), которая представляет совокупную деятельность участвующих в процессе товарного обмена партнеров - изготовителей, посредников, продавцов, покупателей. Развитие ТПС на внешних и внутренних рынках рассматривается как важное конкурентное преимущество МТЗ. Основными направлениями повышения эффективности ТПС являются увеличение продаж через субъекты сети, создание сборочных производств и совершенствование гарантийного и послегарантийного обслуживания реализованной техники.

Товаропроводящая сеть МТЗ сегодня представлена 36 собственными субъектами (торговыми домами и сборочными производствами), в том числе 31 предприятием за пределами Республики Беларусь, а именно: 6 предприятий в Российской Федерации; 2 - в Казахстане; по 1 - в Украине, Молдове и Туркменистане; 11 - в государствах Европейского Союза; 2 - в Латинской Америке (Венесуэла и Бразилия); 2 - в Африке (Египет и ЮАР); 5 - в Азии (Китай, Сингапур, Камбоджа, Пакистан и Турция).

Поддержка субъектов товаропроводящей сети в продвижении продукции осуществляется посредством предоставления различных информационных услуг, продвижения интересов предприятия в различных региональных структурах, обеспечении запасными частями, совместном участии в выставках и ярмарках и др.

Реализация тракторов через субъекты товаропроводящей сети МТЗ представляет собой двухуровневую систему. Первым уровнем являются:

- $\quad$ собственные субъекты сети, созданные в виде акционерных обществ и обществ с ограниченной ответственностью с долей МТЗ в уставном капитале;

- $\quad$ фирмы-агенты (филиалы, представительства);

- $\quad$ сборочные производства (организации, заключившие с МТЗ лицензионные договора на сборку тракторов «Беларус» и осуществляющие дальнейшую реализацию собранной продукции в определенном регионе).

Второй уровень товаропроводящей сети - региональные дилеры, формирующие самостоятельно систему продаж конечному потребителю и обеспечивающие техническое обслуживание техники МТ3 в гарантийный период. 
Одним из лидеров среди предприятий товаропроводящей сети МТЗ является Общество с ограниченной ответственностью (ООО) «Беларус Трактор» («Belarus Traktor» Kft) в Будапеште (Венгрия), которое было основано в 2003 году. Общество создано на идее торгового дома, ориентированного на ведение хозяйственной деятельности и получение прибыли.

Основными видами деятельности ООО «Беларус Трактор» являются:

- продажа тракторов и сельскохозяйственных машин;

- предпродажное и сервисное обслуживание тракторов и сельхозмашин;

- производство и продажа агрегатов и запасных частей к тракторам и сельхозмашинам;

- сборка и ремонт сельскохозяйственной техники.

Фактически предприятие «Беларус Трактор» выступает в роли торгового дома, который имеет свою сервисную и ремонтную базу.

Рынок тракторов Венгрии постоянно развивается. Общая площадь страны составляет 93 тыс. кв. километров, из них обрабатывается 80 тыс. кв. километров. Под пашней находится 4,8 млн га, 1,1 млн га используется под луга и 0,3 млн га - под виноградники и садоводство. Структура венгерского сельского хозяйства состоит, в основном, из фермеров, которые имеют в пределах от 10 до 100 га земли.

Основными конкурентами МТ3 на тракторном рынке Венгрии являются известные производители, такие как John Deer, New Holland, Fend, Massey Fergusson, Claas, Case, Landini, Deutz, Zetor. Однако «Беларус Трактор» сумел найти свое конкурентное преимущество. Венгерские фермеры небогаты, поэтому для них важен уровень цены. Трактора марки «Беларус» предлагаются на рынке значительно дешевле основных конкурентов (до 15 \%), при этом они выполняют те же функции, что и трактора других производителей. В результате цена является основным конкурентным преимуществом МТЗ. Особенно успешно конкурируют на рынке Венгрии трактора «Беларус» малой мощности, имеющие наборы прицепных агрегатов для различных видов сельскохозяйственных работ.

Ситуация на рынке тракторов Венгрии для предприятия «Беларус Трактор» на протяжении 7 лет представлена в таблице 1 .

Таблица 1

Продажа тракторов «Беларус» в Венгрии

\begin{tabular}{|c|c|c|c|c|}
\hline \multirow[b]{2}{*}{ Год } & \multicolumn{4}{|c|}{ Продано тракторов } \\
\hline & $\begin{array}{c}\text { количество } \\
\text { моделей }\end{array}$ & $\begin{array}{c}\text { всего } \\
\text { тракторов }\end{array}$ & 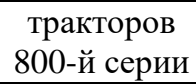 & 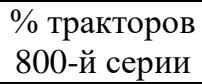 \\
\hline 2012 & 19 & 920 & 693 & 75,3 \\
\hline 2013 & 12 & 1300 & 1198 & 92,1 \\
\hline 2014 & 7 & 1047 & 925 & 88,3 \\
\hline 2015 & 9 & 985 & 812 & 82,4 \\
\hline 2016 & 9 & 687 & 576 & 83,8 \\
\hline
\end{tabular}

Как видно из таблицы, наиболее популярны на рынке Венгрии тракторы «Беларус» 800-й серии. При этом после 2012 года количество моделей тракторов, которые реализовались в Венгрии, резко уменьшилось из-за того, что не все модели соответствовали экологическим требованиям Евросоюза. В частности, двигатели TIER-2 и TIER-3 не соответствовали требованиям. C 2014 года не соответствовали требованиям также двигатели TIER-3A, TIER-3AM. B конце 2016 года были запрещены двигатели TIER3В, и с 2017 года разрешенным остался только двигатель TIER-4. В 2018 году предприятие «Беларус Трактор» временно решило вопрос регистрации трактора «Беларус» 800-й серии, под названием «тихоходный трактор». Это значит, что при регистрации этих тракторов за основу берут не выброс вредных примесей, а мощность и максимальную скорость трактора.

Конкурентную ситуацию, сложившуюся на рынке тракторов Венгрии, отражают итоги 2017 года, представленные на рисунке 1. 


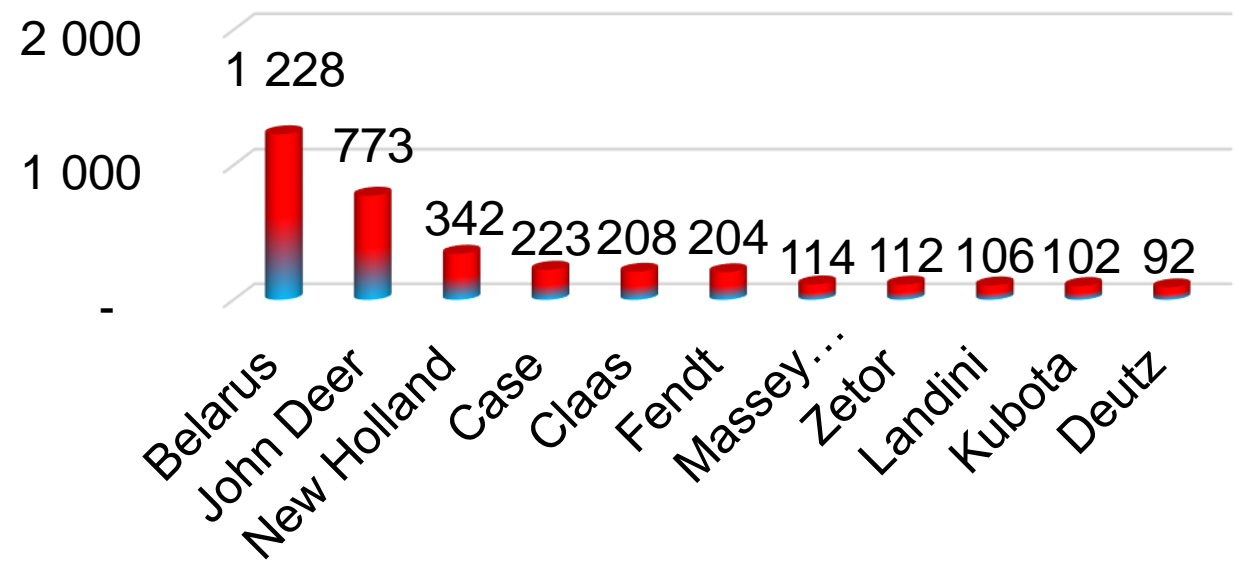

Рис. 1. Продажа тракторов на рынке Венгрии (2017)

Реализация тракторов в зависимости от мощности показывает, что наиболее популярны на рынке Венгрии трактора малой мощности (80-100 лошадиных сил). Их доля в общей реализации составляет около $67 \%$. Объемы реализации тракторов по мощности на рынке Венгрии за 7 лет представлены в таблице 2.

Таблийа 2

Объемы реализации тракторов по мощчности

\begin{tabular}{|c|c|c|c|c|c|c|}
\hline \multirow{2}{*}{ Мощность } & \multicolumn{6}{|c|}{ Год } \\
\hline & $\begin{array}{c}2012, \\
\text { шт. }\end{array}$ & $\begin{array}{c}2013, \\
\text { шт. }\end{array}$ & $\begin{array}{c}2014, \\
\text { шт. }\end{array}$ & $\begin{array}{c}2015, \\
\text { шт. }\end{array}$ & $\begin{array}{c}2016, \\
\text { шт. }\end{array}$ & 2017, шт. \\
\hline Всего тракторов & 920 & 1300 & 1047 & 985 & 687 & 998 \\
\hline 44 kW (60 лс) и меньше & 40 & 23 & 18 & 32 & 29 & 54 \\
\hline 45-66 kW (61-90 лс) & 752 & 1198 & 925 & 849 & 576 & 874 \\
\hline 67-103 kW (91-140 лс) & 123 & 71 & 98 & 98 & 77 & 64 \\
\hline 104-140 kW (141-190 лс) & 4 & 8 & 6 & 6 & 5 & 4 \\
\hline 141-191 kW (191-260 лс) & 1 & - & - & - & - & 1 \\
\hline $192-235 \mathrm{~kW}$ (261-320 лс) & - & - & - & - & - & - \\
\hline 235 kW (320лс) и выше & - & - & - & - & - & 1 \\
\hline
\end{tabular}

В соответствии с требованиями венгерского рынка, трактор «Беларус», особенно малой мощности, является весьма конкурентоспособным. В результате сегодня парк тракторов Венгрии составляет около 130 тыс. шт., из них парк тракторов «Беларус» - около 77 тыс. шт. 
Минский тракторный завод ведет гарантийное и послегарантийное обслуживание тракторов «Беларус» в зарубежных странах на основании агентских соглашений и договоров на обслуживание сервисными центрами и центрами покупки запчастей, а также в рамках контрактов на поставку продукции. В контрактах оговариваются условия гарантий, согласно которым фирма-агент обязана устранять дефекты, а МТЗ компенсировать затраты на основании рекламационных актов.

МТЗ предоставляет полную техническую поддержку, в том числе консультации, составление перечня рекомендуемого оборудования, оказание помощи при ремонте и вводе техники в эксплуатацию, направление специалистов, обучение правилам эксплуатации, квалифицированному техническому обслуживанию и ремонту техники.

С целью снижения времени простоев подготавливаются комплекты запасных частей. Они в качестве обменных фондов находятся в технических центрах и используются для оперативного ремонта тракторов, находящихся на гарантийном обслуживании.

Повышение качества технического обслуживания тракторов в зарубежных странах предусматривает создание новых дилерских центров, проверку и аттестацию существующих, обучение персонала, внедрение новых информационных технологий. МТЗ постоянно ведет работу по заключению договоров с новыми партнерами в зависимости от освоения рынков сбыта и развитию фирменной сервисной сети МТЗ.

Современный мировой рынок тракторов находится в сложной ситуации из-за негативного влияния последствий мирового кризиса. Продажи сельхозтехники всех производителей сократились вдвое. При этом МТЗ удалось сохранить абсолютное лидерство в производстве колесных тракторов на постсоветском пространстве, а также удержать свои позиции на традиционных рынках сбыта.

География поставок за весь период экспортной деятельности МТЗ насчитывает свыше 100 стран. Ежегодно предприятие реализует около 30 тысяч тракторов. В общем объеме производства доля поставок техники за пределы республики оставляет около $96 \%$

На рынке Венгрии предприятие «Беларус Трактор» сегодня ведет продажу техники в 19 областях через дилерскую сеть, которая состоит из 20 дилеров и 47 точек реализации. Сервисное обслуживание тракторов перед продажей осуществляется на ремонтной базе Хорт, где устраняются все возникшие при перевозке техники неисправности.

После продажи каждый трактор и агрегат ставятся на гарантийный учет. На сегодня на гарантийном учете в ООО «Беларус Трактор» одновременно состоит более 3 тысяч тракторов. На предприятии создана база данных по тракторам, стоящих на гарантии. Техническое обслуживание и гарантийный ремонт тракторов и агрегатов выполняют дилеры «Беларус Трактор», имеющие для этого свои ремонтные базы и необходимых специалистов. Наличие возможностей для ремонта предусмотрено дилерскими контрактами.

Контракт между учредителем (МТЗ) и предприятием «Беларус Трактор» предусматривает сбор и анализ сведений обо всех рекламациях и претензиях покупателей техники. С этой целью составляются рекламационные акты, которые отправляются на завод, и на основании которых затем вносятся коррективы в конструкции, технологии, производство и доставку техники.

С целью расширения продаж техники предприятие «Беларус Трактор» ведет активную маркетинговую и рекламную деятельность, в которую непосредственно вовлечены и дилеры. Важнейшим направлением данной деятельности является ивент-маркетинг (событийный сбыт). Ивентмаркетинг заключается в систематической организации мероприятий (событий) как платформы презентации техники с целью привлечения внимания потенциальных покупателей путем эмоционального воздействия на них. Сущность событийного сбыта состоит в комплексе ярких целевых презентационнорекламных мероприятий, направленных на эмоциональное информирование и убеждение потенциальных покупателей. В качестве таких мероприятий могут выступать: выставки, смотры, конкурсы, презентации, праздники и др.

Так предприятие «Беларус Трактор» ежегодно в конце января представляет свою продукцию в Будапеште на международной выставке «Агромаш-Экспо», в которой участвуют ведущие мировые производители тракторов и сельскохозяйственной техники, такие как John Deer, New Holland, Fend, Massey Fergusson, Claas, Case, Landini, Deutz.

В Венгрии в течение года регулярно проводятся региональные выставки сельскохозяйственной техники. Предприятие «Беларус Трактор» через своих дилеров в обязательном порядке представляет на них продукцию марки «МТЗ». Кроме того, крупные дилеры проводят свои собственные выставки («дни открытых дверей») сельхозтехники марки «МТЗ» для потенциальных покупателей.

Предприятие «Беларус Трактор» ведет активную пропагандистскую и коммерческую деятельность в Интернете. Внедрение электронной формы торговли рассматривается как один из инновационных путей развития торговой деятельности. Те возможности, которые дает стремительно развивающийся сектор информационных технологий, предприятие стремится использовать в полной мере и в торговой сфере.

Интернет-маркетинг рассматривается в качестве важнейшего компонента осуществления успешной сбытовой деятельности, который позволяет практически использовать все аспекты традиционной 
рекламы и сбыта в Интернете, затрагивая все основные элементы коммерческой деятельности: производителя, продавца, покупателя, цену, товар, каналы продвижения, место продаж. Задачи интернетмаркетинга предприятия заключаются в том, чтобы держать курс на потребителя, постоянно следить за его пожеланиями и запросами, а также вести мониторинг деятельности конкурентов, определять их сильные и слабые стороны. «Беларус Трактор» осуществляет следующие виды маркетинговой деятельности в Интернете: изучение потребителей и мотивов их поведения; анализ рынков сбыта; исследование продукта; изучение конкурентов; рекламная деятельность; продвижение товаров; использование разных методов продаж через каналы сбыта; анализ объема товарооборота.

На основании данных интернет-маркетинга «Беларус Трактор» корректирует направления совершенствования своей деятельности, а также доводит необходимую рыночную информацию до головной организации - МТ3.

«Беларус Трактор» активно использует инновационные модели интернет-сбыта, в частности: геолокационный и лидогенерационный интернет-сбыт. Геолокационный интернет-сбыт включает охват информацией (локацией) большой круг потенциальных потребителей через Интернет на широкой географической площадке. Это «мобильный сбыт», включающий комплекс акций, мероприятий и кампаний, осуществляемых с помощью мобильных устройств посредством сотовой связи SMS (Short Message Service), для продвижения сельхозтехники к фермерам. Геолокация использует для продвижения продукции в социальных сетях рекламную деятельность, которая позволяет выставить радиус от офиса или дилера, и все пользователи, которые находятся в данном районе внутри этого радиуса, имеют возможность увидеть эту рекламу. Геолокационную рекламу в этом контексте называют «таргетинговой» (целевой) рекламой, суть которой состоит в том, что она позволяет рекламировать конкретные товары вполне определенному сегменту рынка, используя, в том числе, приемы психологического воздействия на целевую аудиторию.

Лидогенерационный интернет-сбыт заключается в привлечении (генерации) потенциальных потребителей (лидов) через Интернет. Привлечение результативных контактов пользователей (собственно, лидов) является предметом деятельности лид-маркетологов и дилеров предприятия. Контактными элементами при этом выступают: номера телефонов, адреса электронной почты или то и другое одновременно. Лиды - это покупатели, которые пришли на сайт, заинтересовались в товаре, и оставили свою заявку или заполнили форму регистрации. Вначале «лид» является потенциальным, а не фактическим покупателем, то есть просто заинтересованным лицом, с которым необходима сбытовая коммуникация. Переход потенциального покупателя в реальный называется в лидогенерации конверсией, которая характеризуется соотношением реальных и потенциальных клиентов. Конверсия равна количеству продаж, деленному на количество квалифицированных лидов.

Предприятие «Беларус Трактор» постоянно рекламирует продукцию марки «МТЗ» в различных сельскохозяйственных изданиях (газеты, журналы), а также посредством собственной печатной рекламной продукции.

«Беларус Трактор» является членом Союза сельскохозяйственных производителей Венгерской республики.

В Венгрии имеется традиция ежегодного проведения соревнований тракторов по пахоте. В них регулярно принимают участие трактора МТ3-820.2, МТ3-892.2, МТ3-952.4 и МТ3-1221.4, которые, как правило, занимают призовые места. Так в своей категории МТ3-820.2 в 2018 году занял первое место.

Благодаря тому, что предприятие «Беларус Трактор» ведет сбытовую деятельность с использованием ивент-сбыта (событийного сбыта), инновационного интернет-сбыта (геолокации и лидогенерации), разнообразной рекламной деятельности, участия в соревнованиях по пахоте и др., финансовое положение «Беларус Трактор» на протяжении ряда лет является устойчивым. Предприятие ежегодно увеличивает прибыль, является успешно действующим на рынке Венгрии предприятием товаропроводящей сети Минского тракторного завода.

\section{Выводы:}

1. ООО «Беларус Трактор» было основано в 2003 году в Будапеште (Венгрия) как дочернее предприятие Минского тракторного завода. Фактически предприятие выступает в роли торгового дома, основными видами деятельности которого являются: продажа тракторов и сельхозмашин; производство и продажа запасных частей и агрегатов; сборка, сервисное обслуживание и ремонт сельхозтехники.

2. Товаропроводящая сеть Минского тракторного завода за границей представлена 31 собственным субъектом (торговыми домами, сборочными производствами, дочерними предприятиями), в том числе: 9 предприятий в странах СНГ; 13 - в Европе; 5 - в Азии; 2 - в Африке; 2 - в Латинской Америке.

3. Структуру сельского хозяйства Венгрии в основном составляют мелкие фермеры, которые имеют от 10 до 100 га земли, поэтому основным спросом пользуются трактора малой мощности, имеющие комплекс навесных агрегатов для различных работ. Трактора «Беларус» выполняют такие же функции, как трактора других производителей, но по цене они значительно дешевле, поэтому пользуются спросом у венгерских фермеров. Трактора «Беларус» занимают 67 \% рынка тракторов Венгрии. 
4. В результате использования инновационных подходов в сбытовой деятельности предприятие «Беларус Трактор» расширяет свое присутствие на рынке Венгрии и становится одним из лидеров товаропроводящей сети Минского тракторного завода.

\section{Список использованной литературы:}

1. Шумилин А.Г. В помощь инноваторам / А.Г. Шумилин // Директор. - 2018. - № 3 (225). - С. 16-17.

2. Можджер В.В. Сбытовая деятельность производственного предприятия на рынке : монография / B.B. Можджер ; под науч. ред. В.Ф. Володько. - Минск : Право и экономика, 2019. - 184 с.

3. Можджер B.B. Ивент-сбыт как инновационная деятельность предприятия / В.В. Можджер // Экономический бюллетень. - 2019. - № 4. - С. 58-67.

\section{References:}

1. Shumilin, A.G. (2018), «V pomoshch' innovatoram», Direktor, No. 3 (225), pp. 16-17.

2. Mozhdzher, V.V. (2019), Sbytovaya deyatel'nost' proizvodstvennogo predpriyatiya na rynke, monografiya, pod nauch. red. Volod'ko, V.F., Pravo i ekonomika, Minsk, 184 p.

3. Mozhdzher, V.V. (2019), «Ivent-sbyt kak innovatsionnaya deyatel'nost' predpriyatiya», Ekonomicheskii byulleten', No. 4, pp. 58-67.

Шумилин Александр Геннадьевич - Председатель Государственного комитета по науке и технологиям Республики Беларусь, доктор экономических наук, доцент.

Можджер Виктор Викентьевич - генеральный директор ООО «Беларус Трактор» в Будапеште.

Статья поступила в редакцию 25.10.2019. 